\title{
Coulisses
}

Revue de théâtre

44 | Printemps 2012

Le Hors-scène

\section{Le Tartuffe de Molière}

Mise en scène de Éric Lacascade, production du Théâtre de Vidy-

Lausanne, Théâtre Musical de Besançon, février 2012

David Ball

\section{(2) OpenEdition}

12 Journals

Édition électronique

URL : https://journals.openedition.org/coulisses/494

DOI : $10.4000 /$ coulisses.494

ISSN : 2546-9460

Éditeur

Presses universitaires de Franche-Comté

\section{Édition imprimée}

Date de publication : 1 juin 2012

Pagination : 177-179

ISBN : 978-2-84867-425-4

ISSN : $1150-594 \mathrm{X}$

\section{Référence électronique}

David Ball, « Le Tartuffe de Molière », Coulisses [En ligne], 44 | Printemps 2012, mis en ligne le 30

novembre 2016, consulté le 29 décembre 2022. URL : http://journals.openedition.org/coulisses/494 ; DOI : https://doi.org/10.4000/coulisses.494 


\section{Le Tartuffe de Molière}

Mise en scène : Éric Lacascade

Production du Théâtre de Vidy-Lausanne

Théâtre Musical de Besançon, février 2012

DAVID BALL

Voici une mise en scène en deux parties nettement contrastées. Avant l'entrée de Tartuffe, une farce bouffonne. Après, la comédie sérieuse que toute la pièce est censée être. Dans la première partie, donc, la farce domine : les bienséances sont ignorées, et même le bon sens semble oublié. Orgon (Jérôme Bidaux) joue toute une scène ses vêtements trempés parce qu'il vient de plonger - pour quelle raison ? - dans un bain. Et cela au moment où la vague de froid sévissait dans toute l'Europe ! Le pauvre homme! Il court et s'agite beaucoup mais tout de même. Quand Valère et Mariane (Simon Gauchet et Noémie Rosenblatt) se réconcilient à la fin de l'acte II, ils s'embrassent de manière si outrée que nous avons presque l'impression qu'ils s'apprêtent à faire l'amour debout sous nos yeux. Dorine (Laure Werckmann) ne se distingue guère de ses maîtres, sauf, peut-être, par l'agressivité de son effronterie. Même Cléante (Arnaud Churin), malgré sa calvitie, n'arrive pas à s'imposer comme centre de gravité.

La calvitie de Tartuffe, par contre, marche à merveille. Éric Lacascade, grand et parfaitement chauve, nous campe un Tartuffe magistral : intelligent, plausible, plein de dignité. Et avec son entrée en scène, la comédie de Molière peut enfin démarrer. Cette pièce est géniale surtout en abordant avec sérieux et justesse une question à la base de toute morale sociale : comment juger les hommes? tout en faisant dérouler l'histoire en une série de rebondissements à la fois comiques et dramatiques, le point culminant étant, bien sûr, la tentative de séduction d'Elmire (Daria Lippi) observée par son mari caché sous la table.

Par contre, le coup de théâtre qui s'ensuit, où Tartuffe met en œuvre l'expulsion de toute la famille de leur maison, n'est pas comique. C'est un moment terrifiant, qui démontre tout le danger qu'il y a à mal juger les hommes. Et comme toujours chez Molière, c'est l'excès qui nous expose au danger. Ici, excès de confiance en l'autre, en son propre jugement de l'autre. Nous autres, 
communs des mortels qui ne savons pas lire dans les cœurs, nous devons nous laisser guider par le bon sens et la modération. Nous jugerons les hommes selon leurs actes, au fur et à mesure que le temps et que notre propre observation les mettent au clair. Dans son dernier coup de théâtre, pourtant, d'un roi, à moitié divin, qui sait lire dans les cœurs, Molière nous gêne en se dévoyant à son tour dans l'excès, celui de la flagornerie. L'intervention du roi, représentant de la loi et de l'autorité de l'État, se justifie, cependant, au moment où la méchanceté de Tartuffe passe de la tromperie morale au crime de tenter de déposséder toute une famille de leurs biens. Comme, ajoutons-nous pour l'actualité, la loi a dû intervenir pour la protection de Mme Bettencourt et de ses biens si importants qu'ils suscitent apparemment toutes les envies et convoitises.

Le décor, signé Emmanuel Clolus, est une construction solide et imposante en bois naturel qui remplit tout le fond et les bords de la scène, une construction à deux étages avec, entre les deux, un large escalier, sans rampe, face au public. Il y a partout portes et rideaux, rideaux qui cachent et portes qui claquent comme dans une comédie de boulevard. À l'étage, comme sur l'escalier, ce sont les membres de la famille qui courent et se poursuivent, tandis qu'au rez-de-chaussée, c'est Tartuffe qui domine et qui impose une certaine lenteur.

Les costumes, signés Marguerite Bordat, sont presque tous en noir et blanc, simples, intemporels. Pour les hommes, chemise blanche avec pantalon et veste longue en noir, et pour les femmes, jupe longue et noire surmontée d'un corsage blanc qui a, pourtant, l'air un peu déconcertant d'un sous-vêtement.

Tous les rôles sont bien assurés par une équipe d'acteurs évidemment très soudée et engagée. Mais il faut signaler plus particulièrement la prestation d'Éric Lacascade, rôle principal aussi bien que metteur en scène. Du bon travail. Et encore une étape passionnante dans l'histoire longue et mouvementée de cette pièce si célèbre, et déjà si attendue en 1669, date de la première représentation, triomphale, de la version que nous connaissons.

Sa première version, qui n'a pas survécu, date de 1664 et fut interdite par le roi pour des raisons conjoncturelles de politique religieuse : qu'il fallait d'abord régler les problèmes posés à l'Église et à l'État par le jansénisme, et que dans ces circonstances une pièce qui pouvait être interprétée comme anti-religieuse tombait mal. Suivirent, donc, cinq années de tractations et de réécritures aboutissant à la version définitive, où l'auteur s'est efforcé à distinguer suffisamment clairement entre la vraie et la fausse dévotion. Question parfois difficile, car la dévotion pouvait être fausse en deux sens. On peut se tromper de bonne foi, comme Orgon, par un excès de naïveté. Ou on peut, comme Tartuffe, tromper les autres volontairement par soif de pouvoir et de reconnaissance. Molière épingle ainsi un risque important de la vraie dévotion, ou de la dévotion vraie à ses débuts : la soumission totale du dévot à son directeur de conscience. Même 
Pascal voulait pratiquer ce genre de soumission, aux risques évidents de se tromper et d'être trompé, vu que n'importe qui pouvait prétendre au rôle.

Molière, en homme du théâtre, se range tout naturellement du côté du plaisir, de l'esthétique plutôt que de l'ascétique, en harmonie en cela avec la cour à cette époque des amours du roi et de son goût affiché du divertissement. Aujourd'hui, pourtant, c'est le texte même du Tartuffe, tout en alexandrins, qui nous demande un effort préalable de dévot littéraire afin de pouvoir accéder à tout le plaisir qu'il a à offrir, effort, nous semble-t-il, que les acteurs et un public nombreux ont été en cette occasion bien prêts à faire. 